\title{
Nasal Cavity and Ethmoid Sinus Cancer Pathologic Primary Tumor TNM Finding v6
}

National Cancer Institute

\section{Source}

National Cancer Institute. Nasal Cavity and Ethmoid Sinus Cancer Pathologic Primary

Tumor TNM Finding v6. NCI Thesaurus. Code C65034.

A pathologic finding about one or more characteristics of nasal cavity and ethmoid sinus cancer, following the rules of the TNM AJCC v6 classification system as they pertain to staging of the primary tumor. 